\title{
PERCURSO DE UMA PESQUISA NA EDUCAÇÃO DE JOVENS E ADULTOS: RODA DE CONVERSA COM ESTUDANTES
}

\author{
RESEARCH COURSE IN YOUTH AND ADULT EDUCATION: \\ CONVERSATION WITH STUDENTS
}

\author{
Ana Paula Junkes ${ }^{1}$ \\ Grazieli Freitas Bordman ${ }^{1}$ \\ Mariana Fogar Lopes ${ }^{1}$ \\ Rutielle Katiane de Paula ${ }^{1}$ \\ Silviana da Silva ${ }^{1}$ \\ Vanessa Cristina Ehrlich ${ }^{1}$ \\ Allan Henrique Gomes ${ }^{2}$ \\ Recebido em: 11 fev. 2019. \\ Aceito em: 16 nov. 2020.
}

\begin{abstract}
RESUMO
Este estudo investigou as concepções de educação dos estudantes do Centro de Educação de Jovens e Adultos, a partir de suas trajetórias de vida. A modalidade de pesquisa adotada foi a pesquisa-ação. Foram realizados três encontros com os estudantes de um Centro de Educação de Jovens e Adultos - CEJA, da cidade de Joinville - SC, utilizando-se de rodas de conversas. Os dados coletados foram transcritos, categorizados e analisados sob o viés da análise de conteúdo. Os resultados foram discutidos a partir das seguintes temáticas: Educação: oportunidade ou direito?; Ruptura e retorno escolar: obstáculos enfrentados nesse processo; A mulher na educação de jovens e adultos; Vínculos, relações e troca de experiências no CEJA. Verificou-se que as trajetórias de vida incidem sobre as concepções de educação dos estudantes, assim como, o percurso escolar constitui tais trajetórias.
\end{abstract}

Palavras-chave: Educação de Jovens e Adultos (EJA); Concepções de educação; Trajetórias de vida.

\section{ABSTRACT}

This study investigated the conceptions of education of the students of the Center of Education of Youths and Adults, from their life trajectories. The type of research adopted was intervention research. Three meetings were held with the students of a Youth and Adult Education Center - JSCA, in the city of Joinville - SC, using talk wheels. The data collected were transcribed, categorized and analyzed under the content analysis bias. The results were discussed from the following themes:

1 Graduação em Psicologia (Universidade da Região de Joinville - UNIVILLE). E-mails: anapaulajunks@gmail.com, grazielibordmann@gmail.com, marianalopespsicologia@gmail.com, rutikatiane@gmail.com, silvianadasilva@yahoo.com.br, vanessa120993@gmail.com

2 Doutor em Psicologia (PPGP/UFSC), docente do PPGE e professor do curso de Psicologia da Universidade da Região de Joinville - UNIVILLE. E-mail: allanpsi@yahoo.com.br 
Education: opportunity or right? Rupture and school return: obstacles faced in this process; The woman in the education of young people and adults; Links, relations and exchange of experiences in the JSCA. It has been verified that the life trajectories affect the conceptions of education of the students, as well as, the school course constitutes such trajectories.

Keywords: Youth and Adult Education; Conceptions of education; Life trajectories.

\section{INTRODUÇÃO}

Em 2015, a Organização das Nações Unidas - ONU, estabeleceu dezessete objetivos de desenvolvimento sustentável para serem alcançados nos próximos quinze anos, de forma a equilibrar as dimensões econômica, social e ambiental. $\mathrm{O}$ quarto objetivo, consiste em "assegurar a educação inclusiva e equitativa e de qualidade, e promover oportunidades de aprendizagem ao longo da vida para todas e todos" (ONU, 2018, web). Nesse sentido, uma das metas versa sobre assegurar que todos os jovens e grande parte dos adultos estejam alfabetizados até 2030.

No Brasil, a Lei de Diretrizes e Bases da Educação Nacional - LDB, estabelece no Artigo 37 a Educação de Jovens e Adultos - EJA, "destinada àqueles que não tiveram acesso ou continuidade de estudos no ensino fundamental e médio na idade própria (BRASIL, 2017, p. 30). A Lei no 9.394/1996 assegura o acesso gratuito aos sistemas de ensino, tendo como exigência para a matrícula, a idade mínima de 15 anos no ensino fundamental, e 18 anos no ensino médio.

O Censo Escolar da Educação Básica de 2017 (G1, 2017) verificou um aumento de $4 \%$ no número de matrículas na Educação de Jovens e Adultos, em relação ao ano anterior, totalizando 2.928 .958 estudantes inscritos no ensino presencial. Além disso, dados do Instituto Nacional de Estudos e Pesquisas Nacionais - INEP (EBC, 2015), referentes ao ano de 2014, mostraram que $30 \%$ dos estudantes dessa modalidade de ensino estão em idade escolar.

Desde a implementação da Educação de Jovens e Adultos, muitos autores têm se proposto a estudá-la. Haddad (1992, p. 2) aponta que o EJA se vincula sobretudo à miséria social, não ao desenvolvimento: "É uma educação para os pobres, para jovens e adultos das camadas populares, para aqueles que são maioria nas sociedades de Terceiro Mundo, para os excluídos do desenvolvimento e dos sistemas educacionais de ensino". 
Por esse motivo, Fonseca (2007) reitera que a Educação de Jovens e Adultos se caracteriza antes por uma especificação sociocultural, do que em sua relação com a faixa etária. A autora, que trata das especificidades e desafios do ensino da matemática para jovens e adultos, assinala assim, que tanto a interrupção de uma trajetória escolar, como a retomada dessa trajetória, acontece em um contexto sociocultural, e as perspectivas quanto a esse cenário culminam em distintas concepções de educação.

Sendo assim, ao realizar uma análise do percurso da Educação de Jovens e Adultos, Machado (2016, p. 446) indaga a respeito desses estudantes: "O que fizemos nesses 20 anos de LDB de 1996 para que de fato eles fossem os protagonistas dessa luta pelo direito a educação, que é deles?". E é por este viés que surge o problema deste trabalho: Quais as concepções de educação dos estudantes da Educação de Jovens e Adultos, a partir de suas trajetórias de vida? Consideramos que é fundamental compreender os significados que esses indivíduos engendram a respeito do papel da educação na sociedade, a partir das suas trajetórias nesse contexto.

Para tanto, realizamos três rodas de conversas, com estudantes de um Centro de Educação de Jovens e Adultos da cidade de Joinville. O método do trabalho e os resultados obtidos serão discutidos a seguir.

\section{PERCURSO METODOLÓGICO}

A pesquisa foi desenhada na forma de uma pesquisa-ação com estudantes de um Centro de Educação de Jovens e Adultos - CEJA na cidade de Joinville - SC com a finalidade de produzir rodas de conversa para conhecer as concepções dos participantes com respeito a educação. Para Gerhardt e Silveira (2009, p.40) citando Fonseca (2002) compreendem que a pesquisa-ação "pressupõe uma participação planejada do pesquisador na situação problemática a ser investigada". E ressaltam a dimensão sistemática do processo de pesquisa, observando a intenção de "transformar as realidades observadas, a partir da sua compreensão, conhecimento e compromisso para a ação dos elementos envolvidos na pesquisa" (idem).

Neste sentido, a pesquisa buscou produzir um espaço de diálogo, sobretudo, de escuta às trajetórias de vida dos estudantes. A possibilidade de encontro com o campo é uma premissa do modo dialógico na produção do conhecimento, que 
compreende a pesquisa como ato narrativo, reflexivo e significativo (GOMES, 2016). Para tanto, optou-se por realizar três encontros com duração de cerca de uma hora, ocorridos com intervalos de 14 dias. No primeiro encontro, foi realizada uma roda de conversa, utilizando um puxa-conversa, com perguntas e frases elaboradas pelas próprias pesquisadoras, a fim de introduzir os participantes ao tema da pesquisa e promover discussões envolvendo suas trajetórias de vida.

Alves et al (2016), explicam a roda de conversa como um instrumento de pesquisa-ação que:

proporciona o diálogo e a interação entre os participantes, estimulando a
reflexão sobre os temas discutidos, a possibilidade de observar as
dificuldades de cada um em relação ao bem viver, colabora com a promoçãa
da saúde, já que o sucesso do método depende da adesão dos participantes
(ALVES et al., 2016, p. 01).

No segundo encontro, atendendo aos pedidos dos participantes, a programação inicial foi alterada a fim de continuarmos utilizando o instrumento de puxa-conversa durante parte do encontro. Ao final deste, explicamos a próxima atividade, na qual cada participante foi convidado a produzir três fotografias que respondessem à questão "O que é educação?". As fotos seriam encaminhadas às pesquisadoras e utilizadas no próximo encontro. No terceiro encontro, devido à falta de adesão dos participantes à atividade com as fotografias, as pesquisadoras pediram para que eles realizassem uma produção que respondesse à mesma questão. Dessa atividade, resultaram textos e desenhos. Em seguida, cada participante falou sobre sua produção e o que esta significava para si.

Os encontros foram realizados na própria instituição de ensino CEJA e foram gravados em áudio e vídeo mediante consentimento livre e esclarecido assinado pelos participantes da pesquisa. A gravação se fez necessária para que as pesquisadoras pudessem analisar com mais qualidade as falas e os dados obtidos através dos encontros, sendo o seu conteúdo transcrito e organizado em uma planilha Excel para a realização da análise das falas.

A transcrição desse material é de suma importância para o sucesso da pesquisa uma vez que, de acordo com Creswell (2014) através das transcrições é possível identificar expressões e frases significativas que se referem diretamente a experiência vivida. As falas foram categorizadas conforme os temas abordados pelos participantes. Surgiram as seguintes categorias: retorno; obstáculos; concepções de 
educação; vínculos; oportunidades; família; EJA (Educação de Jovens e Adultos); Ensino Superior. Foram consideradas para análise as categorias que apareceram com mais frequência no decorrer dos três encontros, bem como as que contemplaram discussões condizentes com os objetivos da pesquisa, sendo elas: retorno, obstáculos, concepção de educação, EJA e vínculos. Os participantes foram nomeados de $\mathrm{P} 1$ à $\mathrm{P} 12$, para resguardá-los em sigilo.

Os dados foram analisados sob o viés da análise de conteúdo. É importante ressaltar que "as pesquisas qualitativas partem do princípio de que a realidade não existe por si só, mas na interpretação que as pessoas fazem da realidade." (MALHEIROS, 2011, p. 206). Sendo assim, as manifestações dos participantes desde falas até as produções gráficas - podem ser compreendidas como expressões das suas interpretações e/ou análises sobre a questão da educação. Dessa forma, as informações colhidas foram interpretadas após a categorização, evidenciando seus conteúdos latentes (GONÇALVES et al, 2014).

\section{RESULTADOS E DISCUSSÃO}

\section{Sentidos da Educação de Jovens e Adultos: segunda chance}

As rodas de conversa oportunizaram aos participantes da pesquisa a possibilidade de compartilharem suas perspectivas sobre a Educação: O que significa estudar em uma escola de jovens e adultos? O que a educação pode proporcionar? O que é necessário para uma educação de qualidade? Entre outras questões contempladas.

Foi possível escutar que os estudantes relacionam a educação de jovens e adultos à ideia de segunda chance. Um dos estudantes refletiu da seguinte forma: "[...] a gente já tá tendo uma segunda chance de estar terminando agora o ensino médio, cada um teve alguma coisa que aconteceu na vida dela pra ela tá aqui [...]' (P7). Outro participante expôs: "[...] se todo mundo tivesse chance de estudar o país já taria num lugar bem melhor." (P6).

Dessa maneira, pode-se entender que a educação não é concebida como um direito, mas como uma oportunidade. É válido lembrar que em uma sociedade marcada por desigualdades sociais, com grandes contingentes de violação de direitos, 
"para essas populações, os direitos humanos são presenças ausentes. Presenças enquanto direito constitucionalmente assegurado, ausência na medida em que não se efetivam" (CAPUCHO, 2012, p. 118-119). Portanto, é presumível que a visão dos estudantes corresponda ao testemunho da ausência de direitos em suas próprias trajetórias. O participante 6 relatou que interrompeu os estudos por dificuldade em conciliar a escola com o trabalho no segundo ano do ensino médio. Ele tentou voltar a estudar há dois anos, mas passou pelos mesmos problemas. O estudante comentou que se arrependeu, pois foi demitido do emprego e experienciou dificuldades para encontrar um emprego, por conta da exigência quanto à escolaridade. Nesse caso, educação e trabalho foram presenças - se não ausentes - vacilantes na vida desse participante.

A partir da trajetória citada, pode-se questionar as contrariedades do sistema capitalista que demanda a realização de uma atividade remunerada de um estudante, mas não inclui o mesmo na escola e após sua exclusão escolar também o exclui do mercado de trabalho (GOMES et al. 2020). Ou seja, discutir EJA é também discutir inclusão. Nesse sentido, Gouveia e Silva (2015) indicam o estabelecimento da educação de jovens e adultos como uma tentativa de o sistema educacional reparar suas dívidas com os sujeitos excluídos. As autoras propõem:

dívidas sociais como a necessidade dos jovens de trabalhar cada vez mais
cedo para sustentar a família e as dívidas pedagógicas, pois percebe-se
também um afastamento dos alunos devido às falhas em um processo
educacional que muitas vezes se mostra discriminatório e incapaz de
envolver o indivíduo de maneira que este se perceba parte do processo
ensino-aprendizagem (GOUVEIA; SILVA, 2015, p. 751).

Assim, a superação da ideia de individuação dos estudantes no tocante à suas trajetórias, bem como a capacidade de refletir sobre a realidade, é importante para que se percebam enquanto atores da sociedade. É válido ressaltar que Paulo Freire, expoente em relação à EJA no Brasil, avaliava que o maior objetivo da educação reside na conscientização do aluno, especialmente no que se refere às populações oprimidas da sociedade (CARDOSO; PASSOS, 2016).

Se por um lado alguns estudantes destacaram a preponderância do trabalho em relação aos estudos no passado, observamos que vislumbram um lugar diferente para a educação em suas trajetórias futuras. É possível perceber no discurso de alguns integrantes do grupo participante certa idealização quanto a concepção de 
educação e seu papel social. Um estudante nos afirmou: "Não é por acaso que quem tem educação pode chegar e sair de qualquer lugar, a qualquer momento" (P12). Esse pensamento indica uma valorização da educação, semelhante a um relato de Lahire, em que o autor explica que determinada família "mantém uma relação ambivalente com a cultura escolar, impregnada de reverência, mas afastada da maioria dos seus pontos de referências" (LAHIRE, 1997, p. 263).

Todavia, há que se considerar que tal concepção é formada a partir da interpretação que esse indivíduo faz da sua realidade e, conforme Faria (2009, p. 3) "partir da realidade significa ouvir o outro e entender seus anseios, compreender o que o outro quer dizer a partir da sua vivência, enquanto sujeito da sua história". O participante em questão almeja ingressar no ensino superior, de tal maneira, que apesar de já ter concluído o ensino médio em um supletivo particular, optou por ingressar na EJA onde conseguirá um diploma certificado pelo MEC e terá a oportunidade de concorrer à bolsas de estudo. A interpretação de que a educação está ligada a um status parece mover sua trajetória. Novamente vemos a concepção de educação distante ao entendimento de direito fundamental.

Outro exemplo de relação com a educação guiada pela ideia de "reverência", pode ser verificado na fala a seguir:

Acho que educação é uma força que a gente tem, é uma coisa que empurra a gente, que a gente precisa. Às vezes a gente nem teria tempo, mas a gente quer tanto, que tem uma força de ir de estudar, porque a gente precisa aprender dos estudos e essas coisas. É a força de Newton [...]. Como ele era um homem que meu Deus! Ficou na história, o que ele fez, eu acho que todo mundo devia ser assim." (P8)

É possível perceber nesta fala uma comparação dos feitos daquele que, na sua visão, ficou para história por seus feitos e esforços. A participante aplica isto para si mesma, com a ideia de construir algo apenas através da educação. A mesma participante mencionou que havia muito o que falar sobre educação, mas que ela não sabia como falar, dizendo apenas: "É uma riqueza, é tudo" (P8). Através dessa fala, é possível observar que embora não conseguisse expressar em palavras, a participante apresenta grande valorização pela educação. Importância essa, apresentada em outras falas no decorrer dos demais encontros.

Além disso, os participantes da pesquisa abordaram diversas vezes a questão do tempo, ora falando do "tempo certo", ora do "tempo errado" e em outros momentos 
da passagem do tempo. Uma participante avaliou da seguinte forma: "Quando você deixa de fazer alguma coisa assim no tempo certo, aí depois você tem que fazer no tempo errado" (P9). A fala pode indicar a responsabilização e individuação que ocupam a leitura dos estudantes sobre as suas próprias trajetórias. Nesse sentido, fica claro nessa passagem a culpabilização da participante por não ter estudado no "tempo certo" - demonstrando ainda, em outros momentos dos encontros, o sofrimento por não ter estudado quando criança. Além disso, esse discurso recai sobre uma representação corriqueira quanto ao "tempo escolar". Conforme Lise e Andreolla (2014, p. 60), "quando se pensa nos sujeitos da educação, remete-se à representação do aluno articulando-a à imagem da criança, que está aprendendo".

Durante os três encontros, os participantes apresentaram concepções de educação com base em suas trajetórias de vida, traçando um paralelo sobre como a exclusão escolar interferiu em suas vidas, especialmente no aspecto econômico. Da mesma forma, expressaram o desejo de voltar ligado a interesses financeiros; ou seja, a educação estaria ligada à oportunidade de ascensão econômica-social. Nesse sentido, muitos dos participantes citaram que o ensino seria a porta de entrada em uma carreira de sucesso e o a exigência de qualificação do mercado de trabalho para cargos com determinada remuneração, motivo este que foi trazido por alguns participantes como sendo sua motivação pelo retorno à escola.

\section{Ruptura e retorno escolar: obstáculos enfrentados nesse processO}

De acordo com a Pesquisa Nacional por Amostra de Domicílios, no ano de 2017, 25,1 milhões das pessoas de 15 a 29 anos de idade não frequentavam escola, ou qualquer outra qualificação ou especialização profissional. Com a taxa de 39,7\%, o principal motivo alegado pelas pessoas era a necessidade de trabalhar (IBGE, 2018).

Outro fator que surgiu nas falas dos discentes que participaram da pesquisa foi a questão familiar. Nesse sentido, surgiram realidades como a de P8, de 38 anos, que interrompeu os estudos aos 10 anos de idade, pois seu pai não via necessidade de uma mulher estudar. Outros relatos que envolvem a questão da família como obstáculos para estudar, trazem questões como ter filhos pequenos que tomam tempo e dedicação, como na fala de P3: "Sou mãe de duas crianças, a gente acorda 5:30 da 
manhã e só vou embora agora $22: 30$ da noite, fico esse tempo todo longe delas". Dessa maneira, observamos especificidades quanto à questão de gênero e por isso, a temática da mulher na educação de jovens e adultos foi abordada em um tópico à parte, logo abaixo.

São citados como obstáculos que causam o afastamento escolar e dificultam o retorno aos estudos: a necessidade de mudar de endereço, indo para longe da escola ou até mesmo para outra cidade, causando reprovação e a desistência dos estudos; a necessidade de cuidar de familiares doentes e; trabalhar para contribuir com a renda familiar.

Questões de natureza sociocultural e econômica, como pobreza, impossibilidade de locomoção, violência e necessidade de trabalhar, foram recorrentes na trajetória de vida dos participantes, apresentando-se como obstáculos para continuidade no estudo regular. Ressalta-se como as questões socioeconômicas caracterizam essa modalidade de ensino, como Haddad (1992, p. 2), expõe, o EJA está diretamente relacionado à miséria social. Nesse aspecto, as dificuldades econômicas juntamente com a dificuldade de conciliar trabalho e escola são mencionados por vários dos participantes como o motivo da ruptura escolar. É possível observar essa dificuldade através do relato do participante (P6):

Hoje consigo conciliar, mas que no ano que fiquei parado não conseguia. Estava trabalhando na época e optei por desistir da escola, por que não estava dando conta dos dois. Tive de conciliar trabalho e estudo desde 2014, na época trabalhava em uma lavação e chegava muito tarde na aula e faltava muito na aula também. Chegou uma hora que tive que optar, e como ajudava em casa dei prioridade ao trabalho. (P6)

Outro aspecto que aparece como possível motivo de evasão escolar é o bullying. Ao qual, Tattum e Tattum (1992), trazem a seguinte definição de bullying como a intencionalidade de ferir uma pessoa, promovendo estresse.

Esse tema surgiu durante a primeira roda de conversa pelo discente P11. Esse diz que: "tem pessoas que na primeira série já sofrem bullying, as pessoas batem nela, coisas do tipo, e aí a pessoa não quer ir pra aula por causa disso, daí tem gente que cresce num ambiente hostil, que pai bate na mãe, ou usa droga [...]".

Muitos foram os motivos apresentados como causas para a desistência escolar, no entanto, de modo geral todos os participantes sentiram a necessidade de retornar para a sala de aula. Esse movimento de retorno é entendido por Souza (1994 
apud Ajala, 2011, p. 20) como uma tomada de consciência acerca da importância dos estudos, afirmando que "ao retornarem à escola, os discentes da EJA percebem o valor do estudo em suas vidas e veem nisso um meio para ascensão social". Essa relação pode ser notada na expressão de P6 quando instigado a falar de seu retorno escolar, dizendo que houve uma "vontade de buscar o saber de novo" (P6). O mesmo participante também mencionou como motivação para retornar aos estudos, a possibilidade de entrar em um mercado de trabalho que julga competitivo, expressando o anseio por ascensão social.

A exigência de qualificação profissional para o mercado de trabalho é o maior motivo entre os alunos para o ingresso no EJA. Para o aluno P6, o trabalho foi o motivo de parar de estudar e foi um dos motivos que o fez retornar. A conclusão do ensino médio configura-se como a esperança de alcançar reconhecimento, autonomia e consequentemente um bom emprego. A escolha entre trabalho ou escola apresentouse fortemente influenciada pela condição financeira da família do estudante.

Nogueira e Nogueira (2002, p. 20) discutem, em relação aos postulados de Pierre Bourdieu, que :

Cada indivíduo passa a ser caracterizado por uma bagagem socialmente
herdada. Essa bagagem inclui, por um lado, certos componentes objetivos,
externos ao indivíduo, e que podem ser postos a serviço do sucesso escolar.
Fazem parte dessa primeira categoria o capital econômico, tomado em
termos dos bens e serviços a que ele dá acesso, o capital social, definido
como o conjunto de relacionamentos sociais influentes mantidos pela família,
além do capital cultural institucionalizado, formado basicamente por títulos
escolares (NOGUEIRA \& NOGUEIRA, 2002, p.20).

As discussões de Bourdieu estão presentes também nos discursos dos estudantes da EJA. O capital cultural é visto como um meio para atingir o capital econômico almejado, mas em contrapartida, muitos se deparam com a necessidade de ter um alto capital econômico para conquistar o capital cultural desejado, que na verdade é um direito garantido, mas, poucos tem acesso. Essa ambiguidade encontrase no leque de fatores que levam jovens e adultos à interromper e retornar aos estudos através da EJA.

Em um estudo realizado por Gomes e Carnielli (2003, p. 51) foi revelada a existência de uma alta proporção de trabalhadores entre os discentes que buscam pelo ensino supletivo da modalidade EJA, traçando um perfil de estudantes jovens, 
migrantes, trabalhadores, com prévia experiência no ensino regular e com pais que predominantemente tem ocupações manuais.

Gomes e Carnielli reforçam que "no seu contexto sociocultural, a educação de jovens e adultos representava uma alternativa importante para eles retomarem a escolaridade, cuja utilidade em termos de trabalho foi destacada [...]". (GOMES; CARNIELLI, 2003, p. 59)

Concluir o ensino médio representa a busca por um futuro melhor, e remete aos estudantes a necessidade de qualificação, diante da concorrência e competitividade do mercado de trabalho. Segundo Schwartzman e Castro (2013, p. 564) "A necessidade de melhor qualificação dos recursos humanos é um requisito da economia e uma aspiração da população, que sabe que as pessoas mais educadas conseguem melhores empregos e melhores rendas".

O retorno aos estudos também apresenta um caráter de valorização pessoal e social. De acordo com Santos (2003, p. 115), o constrangimento social causado pela rotulação de pouca escolarização está entre os motivadores ao retorno para a escola. Isso foi expresso pela fala de P9: "não é só uma vida melhor, é o tratamento que você recebe".

A partir de uma análise geral, nota-se que os principais motivos que fizeram esses discentes retornarem aos estudos foram permeadas por questões trabalhistas, principalmente a necessidade de se tornar competitivo no mercado de trabalho, a fim de conquistar condições melhores de vida para si e para a família.

\section{A mulher na educação de jovens e adultos}

Fernandes et al (2016) destacam que muitas vezes, as mulheres constituem maioria no EJA. No entanto, a presente pesquisa contou com a participação de seis homens e seis mulheres. Durante as rodas de conversas, as participantes do sexo feminino manifestaram questões tocantes às discussões de gênero.

Uma das estudantes, comentou durante um dos encontros: "Lá de casa quem não sabe nada sou eu" (P8). Da mesma maneira, disse que há muito o que se falar sobre educação, mas que ela não sabe o que falar. Nota-se que há uma desvalorização dos seus próprios saberes. Santos (2003) ressalta que essa percepção advém da exclusão escolar e pode ser entendida em um movimento de via 
de mão dupla, na medida em que contribui para uma visão negativa do indivíduo, o move em busca do saber. É possível verificar esse movimento na trajetória da participante, conforme se apresenta a seguir.

A estudante em questão foi excluída do processo de escolarização aos dez anos de idade, quando seu pai julgou que não seria mais necessário estudar. Vimos anteriormente que desenvolveu uma autopercepção negativa, porém, essa participante referiu o desejo de autonomia que a direciona aos estudos:

\begin{abstract}
Eu também, estou buscando um objetivo melhor, eu preciso estudar! Eu não sou uma pessoa de viver só dentro de casa, eu não consigo, eu sempre tenho que ir trabalhar, ir fazer alguma coisa. Eu tenho meu marido, ele fala que eu não preciso ir trabalhar, mas claro que eu preciso! A coisa que eu mais acho difícil: é tudo que a gente quiser tem que pegar com o marido, pegar o dinheiro dele, pra comprar um presente pra ele mesmo! É horrível isso! Então sempre eu quero trabalhar, eu quero um trabalho melhor. Que eu já devia ter estudado, e por isso que não vou me aposentar tão logo". (P8)
\end{abstract}

Os objetivos da estudante em questão, vão ao encontro do que é relatado na produção científica. Fernandes et al $(2016$, p.1) afirmam: "a busca pela qualificação das mulheres se deve principalmente ao fato de almejarem melhores empregos, adquirirem liberdade financeira ou por desejarem manter contato com a sociedade.".

Refletir sobre as pretensões para a retomada dos estudos na vida dessas mulheres é necessário, na medida em que tais objetivos podem ser alcançados, ou não, impactando na permanência delas na escola.

Outro ponto importante, refere-se aos motivos para o abandono dos estudos. Uma das participantes relatou a dificuldade de estudar após tornar-se mãe, por falta de vagas nos Centros de Educação Infantil - CEl's. O relato pode ser relacionado à um estudo do Unibanco, com base nos dados do Instituto Brasileiro de Geografia e Estática - IBGE, $(E B C, 2016)$ que revelou que apenas $2 \%$ das adolescentes que engravidaram deram prosseguimento aos estudos. Santos (2003, p. 122) identifica como um traço de gênero a "característica da situação vivenciada por mulheres das camadas populares que, tendo família constituída, tentam dar prosseguimento à escolarização interrompida anteriormente".

Um dos participantes, do sexo masculino, realizou a seguinte reflexão: "Se os pais de hoje tivessem entendido a importância da educação, de que mulher precisava estudar, hoje seriam diferentes as coisas [...]". (P12). No presente estudo, as mulheres constituíram a faixa etária mais elevada. É possível perceber em que medida estamos 
inseridos em uma sociedade historicamente patriarcal, de modo que os esforços para uma educação inclusiva parecem vacilantes.

Cabe ressaltar que em um contexto educacional que parece não comportar mães, o Ministério da Educação do Brasil pretende retirar o termo "perspectiva da educação inclusiva" da Política Nacional de Educação Especial na Perspectiva da Educação Inclusiva (PNEEPEI), acarretando retrocessos em uma área que vem progredindo arduamente (MANTOAN; SANTOS, 2018, web). Esse cenário é importante para a presente discussão, uma vez a educação inclusiva não se limita aos casos de deficiência, mas diz respeito às várias facetas da exclusão escolar, seja a questão socioeconômica ou o gênero.

\section{Vínculos, relações e troca de experiências no CEJA}

Um aspecto a ser considerado na permanência em sala de aula, visto todos os obstáculos enfrentados pelos estudantes de EJA, são os vínculos. Os participantes da pesquisa demonstraram reconhecer a importância dos vínculos e do laço social nas aprendizagens.

Durante a roda de conversa do primeiro encontro, um dos estudantes respondeu à uma pergunta: "Como era a sua relação com seus professores?" referindo que era boa, entretanto, neste momento o participante passou a pergunta para o seu professor presente em sala, questionando-o como este classificaria sua relação com os alunos, ao que este classificou como ótima: "Quando eu consigo conversar com uma turma de igual para igual, é uma relação ótima." É possível identificar nessa frase do professor a confirmação do que Paulo Freire defendia sobre o diálogo: "Sem diálogo não há comunicação e sem esta não há verdadeira educação" (Freire, 1987, p. 83). Almeida reafirma a declaração de Freire a respeito da importância do diálogo entre aluno-professor:

\footnotetext{
É essencial que aluno e professor mantenham esta relação baseados no diálogo, pois através dele é possível a troca de idéias, dúvidas e até mesmo sentimentos, fazendo com que aluno e professor se conheçam e se compreendam melhor, utilizando de suas diferenças para qualificar seu vínculo e carregá-lo de afeto. $O$ diálogo também melhora consideravelmente o processo de ensino-aprendizagem dentro da sala de aula, pois através desta troca entre os atores é possível repensar cada aula, criar atividades mais atrativas e que atendam as necessidades de toda a turma. (ALMEIDA, 2015, P7).
} 
Durante o terceiro e último encontro os participantes foram convidados a produzir algo que respondesse a pergunta: "O que é educação?", sendo que um dos participantes desenhou o professor de matemática, professor este que cedeu espaço para a realização da intervenção. Quando questionado a respeito do desenho, o participante respondeu:

É eles quem ensinam (...) sem eles tu não é ninguém. é que nem um advogado, o advogado passou por um professor, um policial passou por um professor. O professor passou por um professor! Então eles é quem deviam ser valorizados (...) todo mundo passou por eles. (P5)

É possível observar a existência de um sentimento de afetividade e reconhecimento acerca da importância do docente em sala de aula. Durante toda a intervenção os participantes realizaram várias menções ao professor - talvez por este estar presente na sala de aula durante os encontros, ou pelo afeto por parte dos alunos. De todo modo, pode-se perceber durante as interações dos alunos com o mestre, um vínculo de cumplicidade e respeito.

Neste sentido, o papel do professor não é apenas o de ensinar, mas de acolher os alunos junto com suas potencialidades e dificuldades e buscar proporcionar apoio para manter os alunos em sala de aula, principalmente tratando-se de uma turma de EJA - visto que um alto índice de desistências nessa modalidade. Os estudantes, que já desistiram em algum momento de suas trajetórias acadêmicas, precisam conciliar a escola com outros compromissos como podemos observar na declaração de uma participante:

\footnotetext{
Quando você deixa de fazer alguma coisa assim no tempo certo, aí depois você tem que fazer no tempo errado. Agora tenho que cuidar da casa, do neto, preciso trabalhar, estudar. Mas não deixa de ser, assim, um privilégio, porque eu também, assim, acho que passei muita coisa boa sabe, lá no Félix (antiga escola), muita gente desiste [...]. (P9).
}

Nesse sentido, os autores Loos-Sant'anna e Gasparim defendem que a relação aluno-professor oferece subsídios para que o aluno consiga lidar com situações difíceis, assim como citado pela P9:

A intensificação das relações entre professor-aluno, as formas de
comunicação estabelecidas, os aspectos afetivo-emocionais que se
processam internamente ao indivíduo e permitem a construção de recursos
para lidar com as situações da vida são processos que podem ser
considerados alicerces da construção do conhecimento. (LOOS-SANT'ANNA
e GASPARIM, 2013, P. 200). 
Os vínculos com os colegas de classe e com o professor se mostram muito efetivos no processo de aprendizagem. Para Loos-Sant'anna e Gasparim (2013, p. 200) "a qualidade das interações promovidas no espaço da sala de aula contribuirá, em grande medida, para levar o aluno ao desenvolvimento pleno de suas capacidades, sejam elas cognitivas, afetivas ou motoras". Nesse sentido, os participantes da pesquisa referiram que além de ajudá-los nas tarefas de aula, os amigos os incentivam a ir para aula "É importante ter um foco de amizade até porque um ajuda o outro. E quando tem amizade um motiva o outro a vir" (P10).

Além disso, a diversidade de idades do EJA foi citado como um facilitador para a formação dos vínculos em sala de aula:

Aqui tem uma faixa etária de idade que muda bastante. Tinha um senhor que fazia aula no Ceja do Paraíso que tinha muita dificuldade e os alunos mais jovens o ajudavam. É muito legal isso no Ceja, essa variedade de idades. Porque dá uma ajuda. (P7)

A diferença de idades nesse contexto, aparece como uma via de mão dupla: ao mesmo tempo que os alunos mais velhos citam que os mais jovens os ajudam a compreender as matérias as quais possuem dificuldades, os mais velhos dividem sua experiência de vida com os mais jovens e Ihes oferecem conselhos:

As pessoas que tem 18 e 19 anos que tem todo vigor e força tem que aproveitar, então o que ele falou que acha legal das idades, assim como ele pode me ajudar, eu posso passar experiência pra ele também. Isso aconteceu lá onde eu fiz o nono ano, no Felix, a gente consegue passar experiências para a juventude também, para aqueles que querem aproveitar um conselho bom. (P9)

Conforme observado durante os encontros feitos, percebeu-se que o vínculo afetivo entre os estudantes e entre estudantes e professores, bem como a troca de experiências proporcionadas pelas diversidades de idade e trajetórias de vida tem efeitos positivos na formação dos estudantes da EJA.

Constatou-se ainda, que as relações entre os estudantes em sala de aula colaboram para o aprendizado, na medida em que um estudante mostra ao outro pontos a serem melhorados, colaboram com a diversidade de opiniões, ajudam a motivar e até mesmo manter a atenção nas aulas. Assim, a diversidade de idades encontrada em uma sala de aula do CEJA também é relevante, podendo contribuir para a construção de um conhecimento democrático e humano, aproximando as pessoas e promovendo o diálogo. 
O ser humano é um ser social e de relações. A afetividade e o vínculo desenvolvem-se a partir das relações sociais, daí a importância do vínculo afetivo em instituições educativas. O indivíduo não se desenvolve e aprende sozinho, a construção efetiva do aprendizado se dá pela troca de experiências, em que um indivíduo contribui para a educação e aprendizado do outro.

A afetividade e a ética nas relações entre professor e aluno, são alguns dos aspectos fundamentais, a fim de que ocorra a permanência do estudante da EJA na escola. Relacionamentos afetivos em instituições de ensino voltadas para o retorno a educação representam uma grande força motivacional na vida das pessoas. Os laços afetivos, estruturados e consolidados tanto na escola como na família permitem que os indivíduos lidem com conflitos, aprendendo a resolver os problemas de maneira conjunta ou separada.

É no ambiente social, nas relações com os outros indivíduos e com o produto do seu trabalho historicamente acumulado na cultura, que o homem constrói sua própria individualidade. Afinal, o outro é um elemento necessário para a delimitação e a expansão de si mesmo como pessoa. (ALMEIDA, 1999, p.99)

Os professores que apresentam uma prática pedagógica a favor do aluno, comprometidos com a escola inclusiva, colaboram para que sejam realizadas mediações nos aspectos das diferenças culturais, étnicas, sociais, religiosas, com respeito às diferenças e à pluralidade. A sala de aula precisa ser um ambiente que acolha as diferenças para que os vínculos afetivos sejam de fato saudáveis. Um ambiente que acolhe a diversidade é favorável a aprendizagem e colabora para a continuidade regular dos estudantes na escola.

\section{CONSIDERAÇÕES FINAIS}

A presente pesquisa procurou conhecer e compreender as concepções de educação dos estudantes de um Centro de Educação para Jovens e Adultos, a partir de suas trajetórias de vida. Foi possível identificar que os estudantes, a partir de suas trajetórias de exclusão escolar, em que tiveram tal direito negado, não entendem educação como um direito, mas relacionam à uma questão de oportunidade. Além disso, os obstáculos que encontraram no percurso educacional, como a conciliação dos estudos com o trabalho ou com a família, são também motivações para a retomada. 
Os resultados indicaram que os estudantes que interromperam os estudos por conta do trabalho, esperam conseguir melhores posições no mercado de trabalho a partir da qualificação escolar. No caso das mulheres, que por conta da família foram excluídas do contexto escolar, buscam autonomia por meio da conclusão dos estudos. Outro fator motivador identificado, decisivo para a permanência escolar dos participantes da pesquisa, foi o vínculo: o laço social e a relação com colegas, professores, escola.

Por meio da pesquisa verificamos que as trajetórias de vida incidem sobre as concepções de educação dos estudantes, assim como, o percurso escolar constitui tais trajetórias. Consideramos que esses jovens e adultos precisam ser reconhecidos - e se reconhecerem - como sujeitos de direitos, em uma sociedade marcada pela exclusão, bem como, é preciso uma atenção mais qualificada para a presença das mulheres na educação de jovens e adultos.

\section{REFERÊNCIAS}

BARBOSA, Marialva. História cultural da imprensa - Brasil - 1800-1900. Rio de Janeiro: Mauad X, 2007.

Mauad X, 2010.

História cultural da imprensa - Brasil 1900-2000. Rio de Janeiro:

BARTHES, R. O discurso da história. In: Idem. O rumor da língua. Tradução de Mário Laranjeira. São Paulo: Martins Fontes, 2004a, p. 163-180.

BORGES, Valdeci Rezende. História e Literatura: Algumas Considerações. Goiás: Revista de Teoria da História, Ano 1, n. 3, junho/ 2010.

BUCCI, Eugênio. "A crítica de televisão”. In: MARTINS, Maria Helena (Org.). Rumos da crítica. São Paulo: Editora Senac São Paulo: Itaú Cultural, 2000.

BULHÕES, Marcelo. Jornalismo e literatura em convergência. São Paulo: Ática, 2007

BURKE, Peter. A história dos acontecimentos e o renascimento da narrativa. In:BURKE, Peter (org.) A escrita da História: novas perspectivas. São Paulo: Unesp,

1992

CANDIDO, Antonio. Literatura e sociedade: estudos de teoria e história literária. São Paulo: Nacional, 1976.DELLEUZE, Gilles, GUATTARI, Félix. Mil Platôs: 
capitalismo e esquizofrenia. Tradução de Ana Lúcia de Oliveira. São Paulo: Editora 34, 2005.

CARDOSO, Ciro Flamarion; e VAINFAS, Ronaldo (Orgs). Domínios da história: ensaios de teoria e metodologia. Rio de Janeiro: Campus, 1997.

CERTEAU, Michel de. A Escrita da História. Rio de Janeiro: Forense, 1982

CRUZ, Heloísa de Faria. São Paulo em Papel e Tinta: periodismo e vida urbana 1890-1915. São Paulo: EDUC; FAPESP; Arquivo do Estado de São Paulo; Imprensa Oficial SP, 2000.

DOSSE, François. O desafio biográfico: escrever uma vida. São Paulo. Editora da Universidade Federal de São Paulo, 2009.

FOUCAULT, Michel. A Arqueologia do Saber. Rio de Janeiro: Forense Universitária, 1995.

FOUCAULT, Michel. A Ordem do Discurso: aula inaugural no Collège de France, pronunciada em 2 de dezembro de 1970. 15. ed. São Paulo: Loyola, 2007

JENKINS, Keith. A História Repensada. 3. ed. Tradução de Mario Vilela. São Paulo: Contexto, 2009.

HECK, M. C. The ideological dimension of media messages. In S. Hall, D. Hobson, A. Lowe, \& P. Willis (eds.). Culture, media, language (pp. 122-127). London: Routledge, 1996.

HOBSBAWM, Eric. Sobre história. São Paulo Companhia das Letras, 2013.

LE GOFF, Jacques. História e memória. Campinas: Editora da UNICAMP, 2003.

MALERBA, Jurandir (Org). A História Escrita: teoria e história da historiografia. SãoPaulo: Contexto, 2009.

PÊCHEUX, M. O discurso: estrutura ou acontecimento. Trad. Eni Orlandi. 2 ed. Campinas, SP: Pontes, 1997.

PENA, Felipe. Jornalismo Literário. São Paulo: contexto, 2006.

RIBEIRO, Ana Paula Goulart ; HERSCHMANN, Micael (Orgs.). Comunicação e História: interfaces e novas abordagens. Rio de Janeiro: Mauad X, 2008.

TRAQUINA, Nelson. Teorias do Jornalismo - Porque as notícias são como são. 2. ed. Florianópolis: Insular, 2005.

VICCHIATTI, Carlos Alberto. Jornalismo: comunicação, literatura e compromisso social. São Paulo: Paulus, 2005. 
WHITE, Hayden. Trópicos do Discurso: Ensaio sobre a Crítica da Cultura.Tradução de Alípio Correia de Franca Neto. 2 ed. São Paulo, Editora da USP, 2001, p.137. 